\title{
Morphological Analysis of the Human Lower Extremity Based on the Relative Muscle Weight
}

\author{
By \\ Junji ITO \\ Department of Anatomy, Showa University School of Medicine, Tokyo, Japan \\ - Received for Publication, September 20, 1996-
}

Key Words: Human lower extremity, Relative muscle weight, locomotion

\begin{abstract}
Summary: Morphological study of the muscles of the lower extremity is necessary for the analysis of the muscular function and its relation with locomotion. In this study, the muscle weight of the lower extremities from 11 adult Japanese cadavers (6 males and 5 females, aged from 50 to 91 years old) were measured. The morphological characteristic of the human lower extremity is discussed based on the relative muscular weight. The largest muscles were the gluteus maximus (the extensor at the hip joint), the vasti muscles (the extensor at the knee joint) and the soleus (the plantarflexor at the ankle joint). These results reveal that the muscles acting on one joint are developed in the human lower extremity and that these muscles have important roles in human locomotion.
\end{abstract}

The locomotion patterns of primates are various, ranging from quadrupedalism to brachiation, knucklewalking, and bipedalism, and the muscles of the lower extremity exhibit the morphological features unique to the distinctive locomotion pattern. The characteristic of the human locomotion is erect bipedalism. To elucidate the evolution of human locomotion and the process of the acquisition of the bipedal walking, many studies have been performed by the morphological or the electrophysical method on the muscles of the lower extremities in humans and other primates. The observation of the muscle architecture (origin and insertion), the measurement of the muscle weight, and the analysis of the muscle fiber composition (fiber numbers, size and type) have all been carried out in morphological studies. In these studies, an attempt was made to analyze the functional characteristics of the lower extremity muscles in relation to the locomotion pattern. The muscle weight of the lower extremity in Japanese individuals was measured by Endo (1937). Kimura and Takai (1970) and Ishida (1972) referred to his data in their comparative anatomical studies based on the relative muscle weight. Endo, however, examined only 4 Japanese cadavers $(2$ males and 2 females). In the present study, the muscle weight of the human lower extremity was measured, including the relative muscle weight and the morphological characteristics of the human lower extremity muscles were compared with the locomotion pattern.

\section{Material and Method}

Eleven adult Japanese cadavers ( 6 males and 5 females, ranging in age from 50 to 91 years old) that were supplied for dissection practice at the Showa University School of Medicine were used in this study. Table 1 shows, for each cadaver, the dissected side, age, body weight and total muscle weight in the lower extremity. As the cause of death, neuromuscular disease was not suspected in any of them. All cadavers were fixed by intravascular perfusion through the bilateral femoral arteries with $10 \%$ formalin solution. Dissection of the lower extremity was carried out unilaterally in each cadaver. The muscles were separated at the origin and insertion, and the tendon was cut at the myotendon junction. After removal, the muscle weight was measured on a chemical balance to the nearest $0.01 \mathrm{~g}$ and the following percentages were calculated; the weight percentage for each muscle to the total muscle weight of the lower extremity, and the weight percentage of the segmental muscles at each of the hip, knee and ankle joints.

This work was supported in part by a grant-in-aid for scientific research (06304009) from the Ministry of Education, Science and Culture of Japan. 
Table 1. Subjects of this study

\begin{tabular}{rllccc}
\hline & Sex & Side & $\begin{array}{c}\text { Age } \\
\text { (years) }\end{array}$ & $\begin{array}{c}\text { Body weight } \\
(\mathbf{k g})\end{array}$ & $\begin{array}{c}\text { Muscle weight* } \\
(\mathrm{g})\end{array}$ \\
\hline 1. & Male & $\mathrm{R}$ & 59 & 69.4 & 3246.33 \\
2. & Male & $\mathrm{R}$ & 60 & 56.1 & 4592.25 \\
3. & Male & $\mathrm{R}$ & 61 & 51.2 & 3262.03 \\
4. & Male & $\mathrm{R}$ & 65 & 48.4 & 2677.80 \\
5. & Male & $\mathrm{R}$ & 84 & 59.6 & 2434.10 \\
6. & Male & $\mathrm{R}$ & 91 & - & 2788.84 \\
7. & Female & $\mathrm{R}$ & 50 & 89.8 & 3121.26 \\
8. & Female & $\mathrm{R}$ & 64 & 68.4 & 3334.78 \\
9. & Female & $\mathrm{L}$ & 80 & 38.9 & 1426.00 \\
10. & Female & $\mathrm{L}$ & 85 & 32.3 & 1068.72 \\
11. & Female & $\mathrm{R}$ & 86 & 48.4 & 1689.09 \\
\hline
\end{tabular}

\section{Result}

The mean relative weight percent for each muscle is summarized in Table 2 . The gluteus maximus showed the largest weight percent $(12.83 \%)$ and the plantaris $(0.11 \%)$ the smallest. These results did not show any marked variation among individuals or with aging or sex. The hip, thigh, leg, and foot muscles accounted for $30.44 \%, 46.87 \%, 20.34 \%$ and $2.40 \%$, respectively of the total muscle weight of the lower extremity. Figure 1 shows the weight percentage of each functional segment at each joint. At the hip joint, the extensor muscles were the heaviest $(37.7 \%)$, followed by the adductors $(22.5 \%)$, flexors

* Total muscle weight of the lower extremity

Table 2. Weight percent for each muscle to total lower extremity muscle

\begin{tabular}{|c|c|c|c|c|}
\hline & & Mean & SD & \\
\hline \multirow{9}{*}{ Hip } & M. iliopsoas & 5.89 & 0.360 & \multirow{9}{*}{$\begin{array}{r}\text { Hip total } \\
30.44 \%\end{array}$} \\
\hline & M. gluteus maximus & 12.83 & 1.517 & \\
\hline & M. gluteus medius & 5.87 & 0.793 & \\
\hline & M. gluteus minimus & 2.06 & 0.579 & \\
\hline & M. tensor fasciae latae & 0.94 & 0.285 & \\
\hline & M. piriformis & 0.64 & 0.196 & \\
\hline & M. obturatorius internus & 1.28 & 0.437 & \\
\hline & Mm. gemellis & 0.29 & 0.171 & \\
\hline & M. quadratus femoris & 0.70 & 0.290 & \\
\hline \multirow{15}{*}{ Thigh } & M. sartorius & 1.73 & 0.217 & \multirow{15}{*}{$\begin{array}{c}\text { Thigh total } \\
46.87 \%\end{array}$} \\
\hline & M. rectus femoris & 3.30 & 0.431 & \\
\hline & M. vastus lateralis & 8.40 & 0.818 & \\
\hline & M. vastus intermedius & 3.84 & 1.212 & \\
\hline & M. vastus medialis & 5.65 & 1.086 & \\
\hline & M. pectineus & 0.76 & 0.191 & \\
\hline & M. adductor longus & 2.24 & 0.467 & \\
\hline & M. adductor brevis & 1.59 & 0.192 & \\
\hline & M. adductor magnus & 7.75 & 1.283 & \\
\hline & M. gracilis & 1.02 & 0.246 & \\
\hline & M. obturatorius externus & 1.00 & 0.230 & \\
\hline & M. biceps femoris caput longum & 2.49 & 0.473 & \\
\hline & M. biceps femoris caput breve & 1.42 & 0.175 & \\
\hline & M. semitendinosus & 2.15 & 0.599 & \\
\hline & M. semimembranosus & 3.53 & 0.611 & \\
\hline \multirow{12}{*}{ Leg } & M. tibialis anterior & 2.34 & 0.355 & \multirow{12}{*}{$\begin{array}{r}\text { Leg total } \\
20.34 \%\end{array}$} \\
\hline & M. extensor digitorum longus & 1.15 & 0.282 & \\
\hline & M. extensor hallucis longus & 0.49 & 0.123 & \\
\hline & M. peroneus longus & 1.17 & 0.224 & \\
\hline & M. peroneus brevis & 0.51 & 0.116 & \\
\hline & M. gastrocnemius & 4.26 & 0.418 & \\
\hline & M. soleus & 6.78 & 0.770 & \\
\hline & M. plantaris & 0.11 & 0.067 & \\
\hline & M. popliteus & 0.41 & 0.108 & \\
\hline & M. tibialis posterior & 1.70 & 0.544 & \\
\hline & M. flexor digitorum longus & 0.47 & 0.138 & \\
\hline & M. flexor hallucis longus & 1.11 & 0.184 & \\
\hline \multirow{4}{*}{ Foot } & Muscles of dorsal part of foot & 0.12 & 0.080 & \multirow{4}{*}{$\begin{array}{c}\text { Foot total } \\
2.40 \%\end{array}$} \\
\hline & Muscles of big toe & 0.93 & 0.225 & \\
\hline & Muscles of little toe & 0.37 & 0.157 & \\
\hline & Muscles of central part of foot & 0.91 & 0.280 & \\
\hline
\end{tabular}



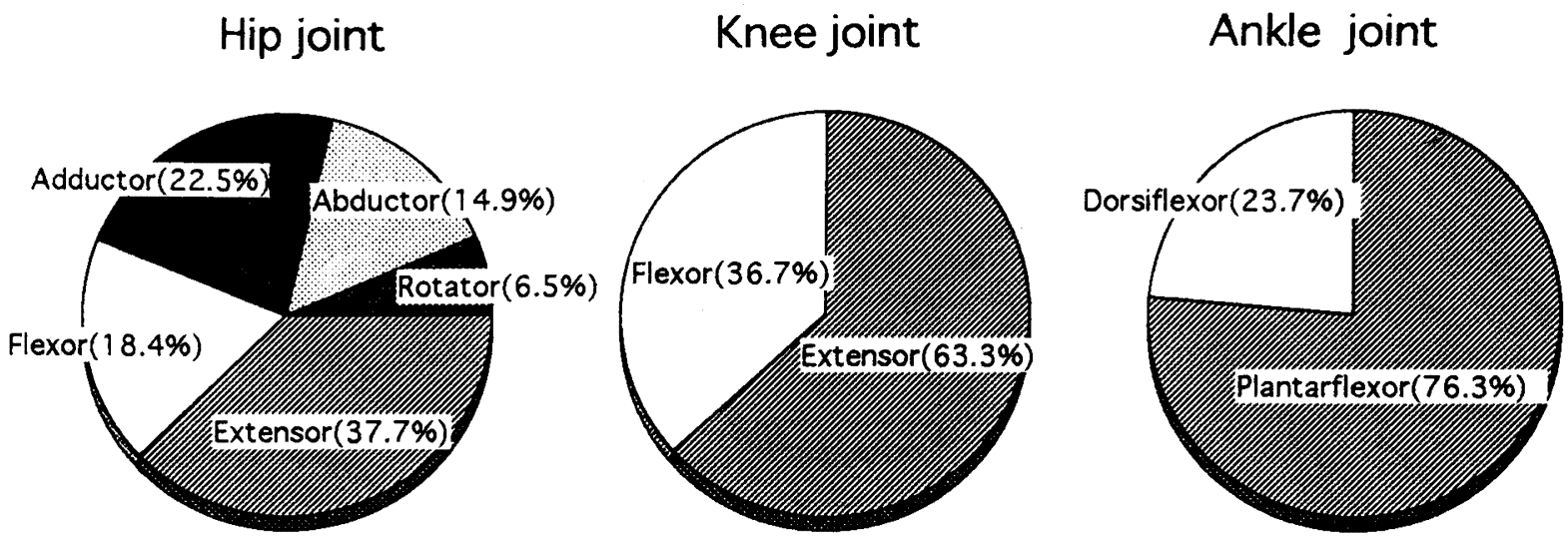

Fig. 1. Functional muscle groups in each joint (Percent of each muscle group).

Hip joint-Flexor; sartorius, rectus femoris, iliopsoas. Extensor; gluteus maximus, biceps femoris, semitendinosus, semimembranosus. Adductor; gracilis, pectineus, adductor longus, adductor brevis, adductor magnus. Abductor; piriformis, gluteus medius, gluteus minimus. Rotator; quadratus femoris, obturatorius externus, gemellus, obturatorius internus.

Knee joint-Extensor; rectus femoris, vastus lateralis, vastus medialis, vastus intermedius. Flexor; semitendinosus, semimembranosus, biceps femoris, gracilis, sartorius

Ankle joint-Plantarflexor; gastrocnemius, soleus, plantaris, tibialis posterior. Dorsiflexor; tibialis anterior, exensor digitorum longus, extensor hallucis longus

$(18.4 \%)$, abductors $(14.9 \%)$ and rotators $(6.5 \%)$. Among the active muscles at the hip joint, the gluteus maximus (an extensor) was the heaviest. At the knee joint, the extensors accounted for $63.3 \%$ of the total weight, and the quadriceps femoris was the heaviest extensor. At the ankle joint, the plantarflexors $(76.3 \%)$ were markedly heavier than the dorsiflexors $(23.7 \%)$. Of the plantarflexor muscles, the soleus was the heaviest.

\section{Discussion}

There is no marked difference between the results found in the present study and those reported by Endo (1937). The heaviest muscle at each joint in the human lower extremity was the gluteus maximus (an extensor) at the hip joint, the quadriceps femoris (an extensor) at the knee joint, and the soleus (a plantarflexor) at the ankle joint. The development

Table 3. Functional indices for lower extremity

\begin{tabular}{lcc}
\hline Index (ratio)* & Man & Monkey** \\
\hline Glut. max./Glut. med. & 222.9 & 37.7 \\
Glut. max./lliopsoas & 222.8 & 39.4 \\
Femoral extensor/flexor & 243.5 & 85.3 \\
Soleus/Gastrocnemius & 161.3 & 38.4 \\
Flex.hall.long./Ext.hall.long & 230.9 & 595.3 \\
\hline * Ratio of muscle weight & \\
** Crab-eating monkey (Kimura and Takai, 1970)
\end{tabular}

of these muscles reveal the distinctive features of the human lower extremity unique to the human locomotion pattern.

Some functional indices for these muscles have been compared in humans and crab-eating monkeys (Kimura and Takai, 1970) (Table 3). The human gluteus maximus is characteristically larger compared to the gluteus medius than that in the monkey and there is an inter-species structural difference for this muscle. The gluteus maximus/iliopsoas ratio, which indicates the extensor function at the hip joint, is markedly larger than in humans. Stern (1972) observed the attachment and structure of gluteus superficialis (gluteus maximus) in monkeys and humans, and confirmed the morphological specialization of the human gluteus maximus at its more cranial portion. The development of the gluteus maximus contributes to the full extension and the stabilization at the hip joint during human locomotion. This feature is thought to be a most important characteristic of human bipedalism.

The femoral extensor/flexor ratio, indicating the extensor function at the knee joint, is much larger in humans than in any other primate except the gibbon, in which it is approximately 400 (Tappen, 1955). The strong extensor function at the knee joint in the gibbon is due to the specialized upright locomotion of the gibbon involving the brachiation and the bipedal locomotion in the arboreal life. In the human thigh, the quadriceps femoris, especially the vasti muscles, are markedly developed. The large vasti muscles, which are muscles acting on one joint (the knee joint), provide the strong extensor power 
needed during human bipedal walking. Analysis by the myofibrous organization revealed that the muscle fiber size of the vasti muscles is larger than that of the rectus femoris, a two-joint muscle within the quadriceps femoris group (Kobayashi, 1991). The hamstring muscles are less weight percentage in humans than in monkeys and this difference is due to the development of the biceps femoris in monkeys. Biceps femoris, however, shows morphological variation among primates. Humans, apes and prehensile-tailed cebids have a biceptal biceps femoris muscle while the other monkeys have a monoceptal ischiocrurali lateralis muscle (Hamada, 1985). Biceps types, which have about $3-4 \%$ relative weight, have the lower weight percentage than monoceptal types, which have above $10 \%$ relative weight (Ishida, 1972). The hind limbs of quadrupeds containing monkeys act as "propulsive lever" (Haxton, 1947) and for this mechanical reason, the strong extensor muscles, particularly the biceps femoris which has the distal expansion of the crural insertion, at the hip joint are required. However, the crural part of the biceps femoris in Japanese monkey contributes to the postural adjustment rather than the propulsive force (Kumakura, 1989a). It was shown that the morphological differences for the biceps femoris are correlated with the locomotion pattern in some primates (Kumakura, 1989b). The human hamstring muscles, especially the semimembranosus and biceps femoris longus, contribute to the postural adjustment, and not to the production of the propulsive force during locomotion. The myofibrous organization of the semimembranosus and biceps femoris longus is the most well developed of the human hamstring muscles (Oohara, 1991). Among the other femoral muscles, the adductor muscles at the hip joint are less weight percentage in humans than in monkeys. At the hip joint, monkeys keep the flexed and abducted position during locomotion, so that the predominance of the adductor muscles are required to stabilize the hip joint.

Of the triceps surae, the soleus is heavier than gastrocnemius in humans while the gastrocnemius and plantaris are heavier in the monkeys. The human soleus is considered a specialized muscle in terms of its origin, expansion to the tibia and the muscle fiber architecture, especially the existence of the bipenniform part. Kumakura and Inokuchi (1991) noted that the soleus is specialized for muscle force production and the gastrocnemius for rapid joint motion at the ankle joint. The large mass of the human soleus must be a requirement for the production of the stronger force required during human locomotion. The human soleus shows the largest muscle fiber size of any human skeletal muscle, and there were characteristic differences between the human and monkey of the soleus and gastrocnemius lateralis (Kataoka, 1989). The specialization of the human soleus muscle is apparent not only from its external features but also in terms of its nerve supply and the intramuscular distribution of nerves (Sekiya, 1991). The large muscle fibers and the presence of the bipenniform part (the partio anterior) and the tibial origin in human soleus contribute to the production of the powerful force for the plantarflexor at the ankle joint. These characteristics have been understood as the results of erect posture and bipedal walking and of the antigravity muscle function. Of the leg muscles, the plantarflexors are more predominant in the weight percentage in humans than in monkeys. In the human locomotion, the lower limb acts as propulsive strut, for which the strong ankle flexors are more important than monkeys, of which the hind limb acts as propulsive lever. The developed flexor digitorum fibularis in the monkey supports the plantarflexor at the ankle joint and parallels the superior grasping ability by the big toe compared to the human toe.

Haxton (1947) and Ishida (1972) showed that the muscles affecting one joint (gluteus maximus, vasti muscles and soleus) are large in humans, while in the monkeys, those acting on two joint (biceps femoris) are large. The one joint muscles of the lower extremity contribute to human locomotion, essentially, by a pattern in which the larger muscles control the more important role of motion at the joint (Grand, 1968). Further analysis of the muscle fiber composition (fiber numbers, size and type) is needed to discuss the relationship between the morphological features of the lower extremity muscles and the locomotion pattern.

\section{References}

1) Endo T. Comparative anatomical observation on the weight of skeletal muscles. Tokyo J Med Sci 1937; 51:1177-1185. (in Japanese)

2) Grand TI. The functional anatomy of the lower limb of the howler monkey. Am J Phys Anthrop 1968; 28:163-182.

3) Hamada Y. Primate hip and thigh muscles: Comparative anatomy and dry weights. In Kondo S (ed.): Primate morphology, locomotor analyses and human bipedalism, pp. 131-152, University of Tokyo Press, Tokyo, 1985.

4) Haxton HA. Muscles of the pelvic limb. Anat Rec 1947; 98:337-346.

5) Ishida $\mathbf{H}$. On the muscular composition of lower extremities of apes based on the relative weight. J Anthrop Soc Nippon 1972; 80:125-145. (in Japanese with English summary)

6) Kataoka J. Comparative studies on muscle structure of the $\mathrm{m}$. triceps surae and $\mathrm{m}$. plantaris in man and monkey. $J$ Showa Med Assoc 1987; 47:833-842. (in Japanese with English summary)

7) Kimura $\mathrm{K}$ and Takai $\mathrm{S}$. Comparative anatomical studies of the extremities of the crab-eating monkey based on the relative muscle weight. Acta Anat Nippon 1970; 45:80-90. 
(in Japanese with English summary)

8) Kobayasi K. Myofibrous organization in human quadriceps femoris muscles. J Showa Med Assoc 1991; 51:186-196. (in Japanese with English summary)

9) Kumakura $H$. Functional significance of the morphology of lateral hamstring muscles of Japanese macaque. J Anthrop Soc Nippon 1989a; 97:513-527. (in Japanese with English summary)

10) Kumakura H. Functional analysis of the biceps femoris muscle during locomotor behavior in some primates. Am J Phys Anthrop 1989b; 79:379-391.

11) Kumakura $\mathrm{H}$ and Inokuchi $\mathrm{S}$. Lay-out of the human triceps surae muscle: with special concern for the origin of the human bipedal posture. Showa Univ J Med Sci 1991;
3:79-89.

12) Oohara $\mathrm{K}$. Myofibrous organization in human hamstring muscles. J Showa Med Assoc 1991; 51:151-158. (in Japanese with English summary)

13) Sekiya S. Muscle architecture and intramuscular distribution of nerves in the human soleus muscle. Acta Anat 1991; 140:213-223.

14) Stern JT. Anatomical and functional specializations of the human gluteus maximus. Am J Phys Anthrop 1972; 36:315-340.

15) Tappen NC. Relative weights of some functionally important muscles of the thigh, hip and leg in a gibbon and in man. Am J Phys Anthrop 1955; 13:415-420. 